\title{
RANGE-WIDE CONSERVATION GENETICS OF BUFF-BREASTED SANDPIPERS (TRYNGITES SUBRUFICOLLIS)
}

\author{
Zachary T. Lounsberry, ${ }^{1,6}$ Juliana B. Almeida, ${ }^{2}$ Tony Grace, ${ }^{1}$ Richard B. Lanctot, ${ }^{3}$ \\ Joe Liebezeit, ${ }^{4}$ Brett K. Sandercock, ${ }^{1}$ Khara M. Strum, ${ }^{1,7}$ Steve Zack, ${ }^{4}$ \\ AND SAMANTHA M. WISELY ${ }^{5,8}$ \\ ${ }^{1}$ Division of Biology, Kansas State University, Manhattan, Kansas 66506, USA; \\ ${ }^{2}$ Ecology Evolution and Conservation Biology Program/MS 314, University of Nevada, Reno, Nevada 89557, USA; \\ ${ }^{3}$ U.S. Fish and Wildlife Service, Migratory Bird Management, 1011 East Tudor Road, MS 201 Anchorage, Alaska 99503, USA; \\ ${ }^{4}$ Wildlife Conservation Society, Pacific West Office, 718 SW Alder Street, Suite 210, Portland, Oregon 97205, USA; and \\ ${ }^{5}$ Department of Wildlife Ecology and Conservation, University of Florida, Gainesville, Florida 62611, USA
}

\begin{abstract}
Range-wide monitoring of shorebirds (Aves: Charadriiformes) suggests that many species are declining. For most species, it is unknown whether distinct population units exist, which makes management and conservation difficult. One shorebird of conservation concern, the Buff-breasted Sandpiper (Tryngites subruficollis), is a New World migrant that breeds at Arctic latitudes in North America and Russia and winters in southeastern South America. We conducted a molecular survey of samples representing each of three migratory regions (breeding, migration, and wintering) using nine polymorphic microsatellite loci and $1.5 \mathrm{~kb}$ of highly variable mitochondrial DNA (mtDNA) from the cytochrome $b$ gene and mtDNA control region. We analyzed contemporary population structure, demographic trends, and phylogeographic patterns. Overall, microsatellite and mtDNA analyses revealed that Buff-breasted Sandpipers are panmictic both regionally and at a global scale, with no signal of a recent genetic bottleneck. The mtDNA analyses revealed a pattern of haplotype diversity consistent with an expansion from a single refugium (Tajima's $D:-2.27$, $P<0.01$; Fu's $\left.F_{\mathrm{S}}:-30.6, P<0.0001\right)$, after the height of the Wisconsinan glaciation $(8,400-45,000$ years before present). Overall, our molecular analyses suggest that Buff-breasted Sandpipers should be treated as a single conservation unit, and management efforts for this species should focus on limiting future declines to ensure that genetic viability is maintained. Received 30 October 2012 , accepted 22 February 2013.
\end{abstract}

Key words: Buff-breasted Sandpiper, microsatellites, mtDNA, phylogeography, population bottleneck, shorebird, Tryngites subruficollis, wader.

\section{Genética de la Conservación de Tryngites subruficollis en Toda su Distribución}

RESUMEN.-El monitoreo de aves playeras (Aves: Charadriiformes) a través de toda su distribución sugiere que muchas especies presentan disminuciones poblacionales. Para la mayoría de las especies no se conoce si existen distintas unidades poblacionales, lo que dificulta su manejo y conservación. Un ave playera de interés para la conservación, Tryngites subruficollis, es un migrante del Nuevo Mundo que se reproduce en latitudes árticas en Norte América y Rusia, y pasa el invierno en el sureste de Sur América. Hicimos un estudio molecular de muestras que representan cada una de tres regiones migratorias (sitios de reproducción, migración e invernada) usando nueve loci de microsatélites polimórficos y $1.5 \mathrm{~kb}$ de ADN mitocondrial altamente variable (ADNmt) del gen citocromo $b$ y la región control del ADNmt. Analizamos la estructura poblacional contemporánea, las tendencias demográficas y los patrones filogeográficos. En general, los análisis de microsatélites y de ADNmt revelaron que T. subruficollis tiene una estuctura poblacional panmíctica tanto a escala regional como a escala global, sin señales genéticas de cuellos de botella recientes. Los análisis de ADNmt revelaron un patrón de diversidad haplotípica consistente con una expansión desde un único refugio $\left(D\right.$ de Tajima: $-2.27, P<0.01 ; F_{S}$ de Fu: $-30.6, P<0.0001)$, posterior a la glaciación del Wisconsiniano (8400-45000 años antes del presente). En general, nuestros análisis moleculares sugieren que las poblaciones de T. subruficollis deberían ser consideradas como una sola unidad de conservación y que los esfuerzos de manejo para esta especie debería enfocarse en limitar los declives poblacionales futuros y asegurar el mantenimiento de su viabilidad genética.

\footnotetext{
${ }^{6}$ Present address: Department of Veterinary Genetics, University of California, Davis, One Shields Avenue, Davis, California 95616, USA. ${ }^{7}$ Present address: PRBO Conservation Science, 3820 Cypress Drive, Suite 11, Petaluma, California 94954, USA.

${ }^{8}$ Address correspondence to this author. E-mail: wisely@ufl.edu
}

The Auk, Vol. 130, Number 3, pages 429-439. ISSN 0004-8038, electronic ISSN 1938-4254. @ 2013 by The American Ornithologists' Union. All rights reserved. Please direct all requests for permission to photocopy or reproduce article content through the University of California Press's Rights and Permissions website, http://www.ucpressjournals. com/reprintInfo.asp. DOI: 10.1525/auk.2013.12206 
RANGE-WIDE ESTIMATES OF population trends for multiple shorebirds (Aves: Charadriiformes) suggest that many species are declining (Morrison et al. 2006, Andres et al. 2012). Declines have been attributed to a number of factors, including market hunting at the turn of the 20th century, continuing loss of suitable habitat, human disturbance, exposure to agricultural contaminants, and climate change (McIlhenny 1943, Butler et al. 2004, Bart et al. 2007, Strum et al. 2010). With many migratory shorebirds experiencing declines over the past centuries, it is essential to identify distinct population segments within a species and the degree of migratory connectivity within populations so that conservation and management are enabled at appropriate scales and locations. Migratory connectivity occurs when certain populations utilize distinct migratory sites, breeding sites, or wintering sites.

Management of shorebirds is often difficult because of the vagile and transient nature of these migratory species. Migratory ecology, rather than physical barriers to gene flow, appears to be important in determining population structure of migratory birds (Liebers and Helbig 2002, Davis et al. 2006, Friesen et al. 2007, Pearce et al. 2009). For shorebirds, determining population structure and migratory connectivity is especially challenging because of low rates of band resighting $(<0.01 \%)$, lack of morphological differences among populations, and small body size that prevents deployment of satellite transmitters (Haig et al. 1997, Webster et al. 2002, Lanctot et al. 2009, Clark et al. 2010). Intrinsic markers, such as molecular and stable isotope markers, offer an indirect approach to ascertain population structure and connectivity.

Molecular techniques can identify cryptic population structure that typically cannot be detected by observational approaches alone. Stable isotope analyses and other non-genetic methods of assessing connectivity provide a relatively coarse resolution of patterns of migratory ecology (Franks et al. 2012). The advantage of genetic techniques is that they allow us to assess patterns of historical phylogeography and contemporary population structure so that conservation efforts can focus on the preservation of two important conservation units: management units and evolutionarily significant units (Moritz 1994). In the past two decades, migratory bird conservation has relied heavily on defining conservation units to limit the loss of cryptic populations (Haig et al. 2011). Several phylogeographic studies have suggested that late Pleistocene glaciation events have been largely responsible for shaping distinct evolutionarily significant units in Arctic-breeding migratory shorebirds, including Dunlin (Calidris alpina; Wenink et al. 1996) and Temminck's Stint (C. temminckii; Rönkä et al. 2012). Population genetic analyses of migratory birds have also revealed more contemporary population processes that contribute to population structure and used these data to define distinct management units. Wennerberg et al. (2008) found distinct management units in Southern Dunlin (C. a. schinzii) based on contemporary allele frequencies and recommended conservation of multiple populations. The presence of management units has also informed conservation efforts of Temminck's Stint (Rönkä et al. 2008). For migrant species, the detection of genetically distinct conservation units is crucially important in management efforts focused on maintaining genetic diversity and population viability.

Shorebird conservation is also hindered by uncertainties in estimating sizes and trends of populations. Obtaining precise estimates is difficult because animals are unevenly distributed, there is a potential for variation in migration routes and movement rates, and logistical constraints make monitoring difficult in remote areas (Bart et al. 2007, Lanctot et al. 2008). These limitations are common for shorebirds, often resulting in large confidence intervals around population estimates (Andres et al. 2012). An alternative to using observational techniques is to estimate the idealized number of breeders in a population with the same genetic characteristics as the study population (i.e., effective population size, $N_{\mathrm{e}}$ ). This metric can be used as a proxy for population health by comparing the estimated $N_{\mathrm{e}}$ to a threshold minimum value required to sustain genetic viability.

One shorebird of conservation concern, the Buff-breasted Sandpiper (Tryngites subruficollis), is a New World migrant that winters on the pampas in southeastern South America and breeds sporadically along the Arctic coasts of Russia, Alaska, and Canada (Fig. 1; Lanctot et al. 2010). Buff-breasted Sandpipers migrate both northward and southward primarily along the Central Flyway of the United States and over central South America; small numbers of birds use the Eastern Flyway during fall migration as well (Fig. 1; Skagen et al. 1999, Lanctot et al. 2010). This historically abundant species experienced sharp population declines in the late 1800s and early 1900 s, when it was commercially hunted in the midwestern United States during migration. More recently, declines have been attributed to habitat loss of upland grassland habitat as it is converted into agriculture (Lanctot and Laredo 1994; Page and Gill 1994; Lanctot et al. 2002, 2010). Currently, the species is listed as "near threatened" by the IUCN (BirdLife International 2009) and is considered "highly imperiled" by the U.S. Shorebird Conservation Plan (2004), a designation shared by only 4 of 54 North American

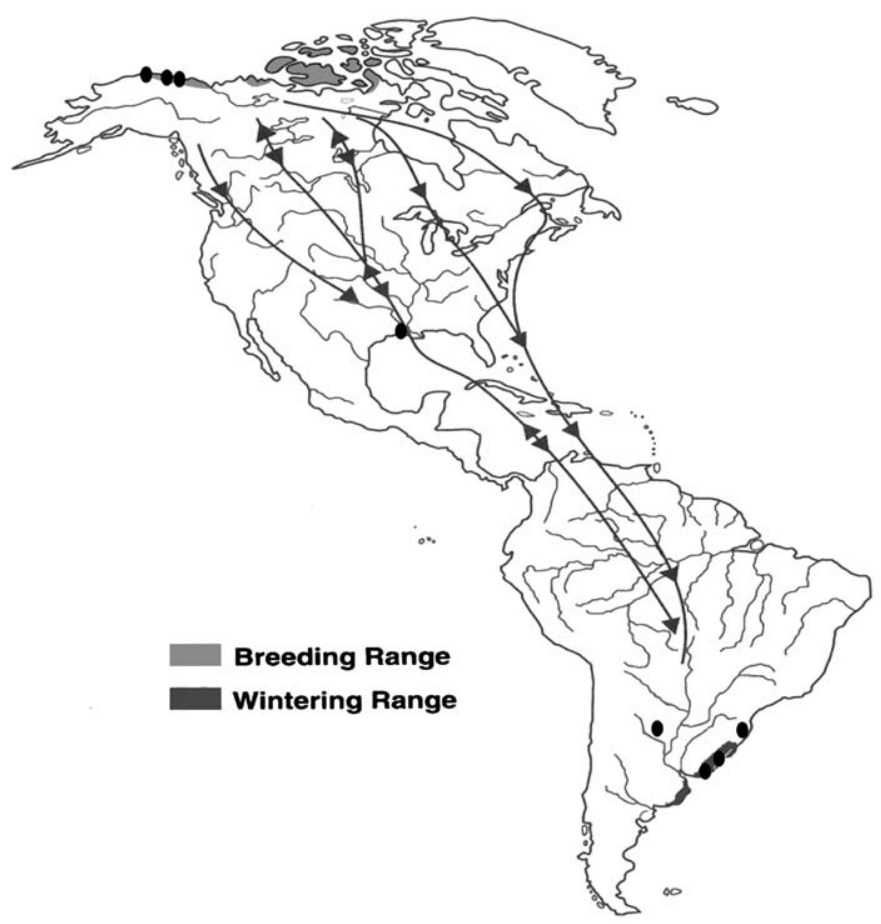

FIG. 1. Range map for the Buff-breasted Sandpiper. Shaded areas in North America and South America represent the species' breeding and wintering regions, respectively. Solid black lines represent primary migratory routes. Filled black circles indicate sampling sites. Map excerpted from Lanctot et al. 2010. 
species of shorebirds. The most recent population estimate for the Buff-breasted Sandpiper is 56,000 individuals (range: 35,00078,000; Lanctot et al. 2010, Andres et al. 2012). Threats to contemporary Buff-breasted Sandpiper populations include habitat loss or degradation throughout their breeding, migration, and wintering regions, which may be compounded by the negative effects of climate change that could increase mortality throughout the annual migration route (Lanctot et al. 2010, Strum et al. 2010).

The goal of our study was to investigate the conservation status of Buff-breasted Sandpipers using a population genetics approach. We examined the degree of genetic connectivity among and within the three major regions of the species' annual cycle: breeding, migration, and wintering. Because this species has low site fidelity to breeding regions in the Arctic, we expected to see little genetic population structure among breeding sites (Lanctot et al. 1997). By contrast, we predicted the possible presence of sex-biased genetic structure at wintering regions resulting from the relatively high wintering-site fidelity observed in female Buffbreasted Sandpipers (Almeida 2009). In addition, we assessed population structure in the Central Flyway to detect unique genetic signals that might be associated with unsampled breeding or wintering sites. Birds from all parts of the breeding and wintering range visit relatively few migration sites, increasing the likelihood of obtaining a representative sample of the global population from these areas. We tested for genetic structure across the entire range of this species, as well as within regional breeding and wintering regions, to uncover potentially cryptic conservation units for management. In addition, we assessed the role of glacial cover and climate changes associated with events in the Late Pleistocene and Holocene on contemporary population structure and taxonomic status. Last, we calculated estimates of genetic effective population size $\left(N_{\mathrm{e}}\right)$ and conducted analyses of demographic trends to provide a more comprehensive picture of the demographic history and conservation status of this species.

\section{Methods}

Study sites.-We sampled breeding Buff-breasted Sandpipers ( $n=$ 206) at leks and solitary sites at three locations between 1993 and 2009 (Fig. 1). Sampling sites encompassed a 315-km portion of the Arctic coast of Northern Alaska and included Barrow $\left(71.30^{\circ} \mathrm{N}, 156.77^{\circ} \mathrm{W}\right)$, Canning River $\left(70.07^{\circ} \mathrm{N}, 146.71^{\circ} \mathrm{W}\right)$, and Prudhoe Bay $\left(70.33^{\circ} \mathrm{N}, 148.71^{\circ} \mathrm{W}\right)$. We captured adults with mist nets on leks and with bow nets at nest sites. Between 2006 and 2007, we captured migrating Buff-breasted Sandpipers along the Central Flyway of the United States using mist nets, drop nets, and spotlights with dip nets (Strum 2008; Fig. 1). Birds sampled from migration sites were sampled during both spring ( $n=21$ birds) and fall ( $n=21$ birds) migration at the Anahuac National Wildlife Refuge in Texas $\left(29.34^{\circ} \mathrm{N}, 94.32^{\circ} \mathrm{W}\right)$. In South America, we captured wintering birds using drop nets in Uruguay $\left(34.40^{\circ} \mathrm{S}, 54.17^{\circ} \mathrm{W}\right)$ and Argentina $\left(30.32^{\circ} \mathrm{S}, 62.17^{\circ} \mathrm{W}\right.$; see details in Strum et al. 2010). We also captured birds at nocturnal roosts at wintering sites in Brazil from 2001 to 2005 using spotlights and dip nets (Fig. 1; Almeida 2009). These samples represented individuals from two sites in Brazil separated by $\sim 350 \mathrm{~km}$ : Lagoa do Peixe $\left(30.25^{\circ} \mathrm{S}, 50.96^{\circ} \mathrm{W}\right)$ and Taim $\left(32.59^{\circ} \mathrm{S}, 52.59^{\circ} \mathrm{W}\right)$.

Our sampling scheme allowed us to document the overall genetic diversity of the global population of Buff-breasted
Sandpipers. This was especially true on the wintering region, where capture efforts took place throughout much of the range (Fig. 1; Lanctot et al. 2002). By contrast, we sampled only a portion of the species' breeding region in Alaska and were unable to sample breeding sites in Russia or Canada. To capture signatures of genetic diversity that we potentially missed by sampling only a portion of the breeding region, we sampled birds in the flyway. Most of the global population funnels through the Central Flyway in the Great Plains of North America during migration (Jorgensen et al. 2008, Lanctot et al. 2010). Detection of private alleles unique to birds sampled at migration and wintering sites and absent from birds sampled at the breeding sites would indicate unsampled, distinct breeding populations.

Sample collection.-All birds had $50-200 \mu \mathrm{L}$ of blood drawn with micro-hematocrit capillary tubes following venipuncture of the brachial vein with 27.5- to 28-gauge needles. We extracted genomic DNA from breeding-site blood samples using a DNeasy Blood and Tissue Kit (Qiagen, Valencia, California). DNA from migration and wintering samples was available from previous molecular work with these samples (Almeida 2009, Strum et al. 2010).

Microsatellite amplification.-We surveyed a total of 40 candidate microsatellite loci (11 developed for Pectoral Sandpipers from Carter and Kempenaers [2007] and 29 developed for Buffbreasted Sandpipers in our laboratory) to establish genotype profiles for all individuals. Of 40 candidate loci screened, we used two novel loci developed in our laboratory (6A3F: 5'-TGAGT TTAAAGCCTCAGAGC-3'; 6A3R: 5'-CACACAAGACCCT GGTAACT-3'; 6A12F: 5'-GTGCTGCCAGAAGAAATCAC-3'; 6A12R: 5'-CAGACGAAATGGCTCGATAT-3'; GenBank accession nos. JX123420 and JX123421) and seven loci from Carter and Kempenaers (2007). The nine loci consistently amplified using polymerase chain reaction (PCR) and were polymorphic (Table 1).

For molecular analyses, we prepared PCR mixtures with 20100 ng genomic DNA, $2 \mu \mathrm{L} 1 \mathrm{X}$ reaction buffer (PROMEGA), $2 \mathrm{mM}$ $\mathrm{MgCl}_{2}, 0.2 \mathrm{mM}$ of each dNTP, $0.5 \mu \mathrm{M}$ of reverse primer (Table 1 ), $0.3 \mu \mathrm{M}$ of forward primer, and $0.3 \mu \mathrm{M}$ of $\mathrm{M}-13$ universal primers (Schuelke 2000) labeled with a fluorescent dye attached to the $5^{\prime}$ end (Operon Biotechnologies, Huntsville, Alabama), $0.1 \mu \mathrm{g}$ bovine serum albumen (BSA), and 0.1 units of GoTaq polymerase (PROMEGA). We denatured mixtures in an Eppendorf Mastercycler Pro thermal cycler (Brinkman, Westbury, New York), for one 4-min cycle at $94^{\circ} \mathrm{C}$ followed by 30 thermal cycles combining a 30-s denaturation step at $94^{\circ} \mathrm{C}$, a 30-s annealing step at $\mathrm{Tm}^{\circ} \mathrm{C}$ (Table 1 ), and a 30 -s extension at $72^{\circ} \mathrm{C}$ followed by another 10 thermal cycles combining a 30 -s denaturation step at $94^{\circ} \mathrm{C}$, a 30 -s annealing step at $54^{\circ} \mathrm{C}$, and a 30 -s extension at $72^{\circ} \mathrm{C}$, and a final extension step for $10 \mathrm{~min}$ at $72^{\circ} \mathrm{C}$. We multiplexed PCR products for fragment analysis and sized fragments against 500-LIZ size standard (Applied Biosystems). We used GENEMARKER, version 1.95 (Soft Genetics, State College, Pennsylvania), to visualize amplified fragments. We reran samples that were scored as homozygotes, as well as a random subset of $10 \%$ of heterozygotes to assess allelic dropout rates.

Mitochondrial DNA amplification.-We amplified a total of 1,543 base pairs (bp) of mitochondrial DNA (mtDNA) for two variable regions using primers described in the Appendix. The region comprised the cytochrome $b$ gene (hererafter "cyt $b$ "; $967 \mathrm{bp}$ ) and $576 \mathrm{bp}$ at the $5^{\prime}$-end of the mitochondrial control region. We amplified these regions using PCR mixtures at a volume of $10 \mu \mathrm{L}$ 
TABLE 1. Characterization of microsatellite loci used to genotype Buff-breasted Sandpipers $\left(N_{\mathrm{A}}=\right.$ number of alleles, $\mathrm{Tm}=$ annealing step temperature, $H_{\mathrm{o}}=$ observed heterozygosity, and $H_{\mathrm{E}}=$ expected heterozygosity). $H_{\mathrm{o}}$ values with an asterisk indicate loci that show significant deviation from Hardy-Weinberg equilibrium (Bonferroni corrected $P<0.01$ ).

\begin{tabular}{lcccccc}
\hline Locus ID & Repeat motif & $N_{\mathrm{A}}$ & $\mathrm{Tm}\left({ }^{\circ} \mathrm{C}\right)$ & Allele size $(\mathrm{bp})$ & $H_{\mathrm{o}}$ & $H_{\mathrm{E}}$ \\
\hline 6A12 & $(\mathrm{CT})_{11}$ & 4 & 58 & $247-259$ & $0.356^{*}$ & 0.431 \\
6A3 & $(\mathrm{TCTT})_{5}$ & 8 & 56 & $212-226$ & $0.711^{*}$ & 0.745 \\
CME1 & $(\mathrm{CA})_{19}$ & 9 & 58 & $102-120$ & 0.755 & 0.787 \\
CME2 & $(\mathrm{GT})_{15} \mathrm{AT}(\mathrm{GA})_{3}$ & 7 & 58 & $155-171$ & 0.415 & 0.423 \\
CME6 & $(\mathrm{CA})_{8}$ & 18 & 61 & $201-235$ & $0.554^{*}$ & 0.888 \\
CME8 & $(\mathrm{CA})_{6}$ & 12 & 61 & $209-235$ & $0.480^{*}$ & 0.764 \\
CME9 & $(\mathrm{GT})_{13}$ & 3 & 61 & $161-165$ & 0.317 & 0.320 \\
CME10 & $(\mathrm{CA})_{14}$ & 5 & 56 & $202-210$ & 0.327 & 0.348 \\
CME12 & $(\mathrm{CT})_{3}(\mathrm{GT})_{13}$ & 14 & 56 & $192-218$ & 0.755 & 0.740 \\
Mean $\pm \mathrm{SD}$ & & $8.89 \pm 4.96$ & & & $0.519 \pm 0.182$ & $0.605 \pm 0.220$ \\
\hline
\end{tabular}

that contained 20-100 ng genomic DNA, $2 \mu \mathrm{L} 1 \mathrm{X}$ reaction buffer (PROMEGA), $2 \mathrm{mM} \mathrm{MgCl} 2,0.2 \mathrm{mM}$ of each dNTP, $0.5 \mu \mathrm{M}$ of each primer (Appendix), $0.1 \mu \mathrm{g}$ bovine serum albumen (BSA), and 0.1 units of GoTaq polymerase (PROMEGA). We denatured these reactions for one 2 -min cycle at $95^{\circ} \mathrm{C}$ followed by 30 thermal cycles combining a 30 -s denaturation step at $94^{\circ} \mathrm{C}$, a 30 -s annealing step $\left({ }^{\circ} \mathrm{C}\right.$, Appendix), a 30 -s extension at $72^{\circ} \mathrm{C}$, and a final extension step for $10 \mathrm{~min}$ at $72^{\circ} \mathrm{C}$. We bidirectionally sequenced PCR products at the University of Kentucky AGTC Sequencing Center via BigDye reactions using the same forward and reverse primers used in amplification.

We compiled consensus sequences from our forward and reverse sequences in BIOEDIT, version 7.0.5.3 (Hall 1999). We then aligned consensus sequences for each of the five amplified regions using a ClustalW approach and by eye in the program MEGA4 (Tamura et al. 2007). We assembled the three segments of cyt $b$ and two segments of the control region, respectively, for phylogenetic analyses. We deposited sequence data for all novel haplotypes in GenBank (accession nos. JX121967-JX122073).

Microsatellite analyses of genetic diversity and structure.We analyzed microsatellite characteristics across all individuals with complete genotype profiles using several software packages ( $n=477$ sandpipers). For table-wide analyses of significance, we used a sequential Bonferroni correction for multiple pairwise comparisons (Rice 1989). We calculated the number of alleles $\left(N_{\mathrm{A}}\right)$, size ranges, and number of private alleles using MICROSATELLITE TOOLKIT, version 3.1.1 (Park 2001). We performed exact locus-by-locus tests for deviation from Hardy-Weinberg equilibrium (HWE) using a 1-million-step Markov chain Monte Carlo simulation in ARLEQUIN, version $3.5\left(H_{\mathrm{o}}\right.$ and $H_{\mathrm{e}}$ values given in Table 1; Excoffier et al. 2005). We also tested for pairwise linkage disequilibrium (LD) between all microsatellite loci using Fisher's exact test with 5,000 permutations in ARLEQUIN. Four loci deviated significantly from HWE (Table 1), and we conducted all subsequent microsatellite tests that assume HWE without these loci. We also assessed the possible presence of null alleles using a homozygosity excess test in MICRO-CHECKER, version 2.2.3 (van Oosterhout et al. 2004).

We used several independent approaches to assess population substructure. We used a Bayesian clustering approach assuming
$K=1$ through $K=5$ (where $K=$ number of putative populations) in STRUCTURE, version 2.3 (Pritchard et al. 2000). We performed this analysis on the entire sample population with and without defining putative populations. To assess migratory connectivity, we defined putative populations using each region: breeding, migration, and wintering. We supplemented the Bayesian clustering method with a descriptive approach to assess genetic differentiation using a two-dimensional principal coordinate analysis (PCoA) based on genetic distance using all nine loci, implemented in GENALEX, version 6.3 (Peakall and Smouse 2006).

To test our hypothesis regarding within-region genetic structure, we performed Bayesian clustering analyses and PCoA among the four sites within the wintering region (Argentina: $n=5$; Uruguay: $n=14$; Taim: $n=39$; Lagoa do Peixe: $n=195$ ) and among the three sites within the breeding region (Prudhoe: $n=153$; Barrow: $n=15$; Canning: $n=10$ ). In addition, we tested for sex-specific population structure among wintering sites. Females were more likely to return to wintering sites than males, so we excluded males and partitioned females between our two Brazilian wintering sites to examine possible genetic structure among females (Almeida 2009). All migration samples were collected in the southern portion of the Central Flyway (Texas). To determine whether there were population-specific seasonal differences in migration site use, we separated migrating individuals between spring and autumn collections. We supplemented analyses of genetic structure with Wright's $F$ statistics and performed analyses of molecular variance (AMOVA) among sites in ARLEQUIN.

Population trend analyses.-To determine whether samples from the 1990s and 2000s had similar genetic structure, we partitioned our global sample by decades. Breeding samples from the 1990 s $(n=65)$ were treated as a separate population from samples collected in the 2000s $(n=412)$, and we determined whether any alleles had been recently lost. We used microsatellite data to estimate $N_{\mathrm{e}}$ for our population of Buff-breasted Sandpipers. Using an LD method implemented in the programs LDNE, version 1.31 (Waples and Do 2008), and NEESTIMATOR, version 1.3 (Peel et al. 2004), we calculated point estimates and 95\% confidence intervals for $N_{\mathrm{e}}$. In LDNE, we excluded alleles with a frequency $\leq 0.001$ (i.e., singleton private alleles). We chose the LD method over the temporal method because, for the latter to be applicable, 
samples should be 5 to 10 generations apart for the influence of drift to be greater than the sampling error for that population (Waples and Yokota 2007). Also, the bias associated with sampling a large, panmictic population multiple times over small intervals was unpredictable (Waples and Yokota 2007).

Buff-breasted Sandpipers have been subject to a variety of recent perturbations, and we used two independent methods for detecting a genetic bottleneck from our genotypic data. We used the $M$-ratio method, which relates the total number of alleles to the overall range in allele sizes. Using the conservative parameterization suggested by Garza and Williamson (2001) for the two-phase mutation (TPM) model, we assumed a proportion of multistep mutations $\left(p_{\mathrm{g}}\right)=0.10$, an average size of multistep mutations $\left(\Delta_{\mathrm{g}}\right)=$ 3.5 , and a mutation rate $(\mu)$ of $5.0 \%$ mutations per locus per generation. Pre-bottleneck estimates of $N_{\mathrm{e}}$ were not known for this species, but this value is required to estimate critical threshold values of $M\left(M_{\mathrm{c}}\right)$. Thus, we used a range of estimated pre-bottleneck $N_{\mathrm{e}}$ to calculate a range of $\theta$ (where $\theta=4 N_{\mathrm{e}} \mu$ ) and tested for $M$ across this range. We found the $M$ ratio for each locus and averaged this value over all loci using the program M_P_VAL (Garza and Williamson 2001). When compared with $M_{\mathrm{c}}$ thresholds (generated using the program CRITICAL_M), the $M$ ratio can be used to differentiate between a recent population bottleneck and a population that has remained small over time (Garza and Williamson 2001). Our second method for assessing signals of a genetic bottleneck was to use a mode-shift indicator and a test for heterozygosity excess under the TPM model in BOTTLENECK (Cornuet and Luikart 1996). Using the same conservative parameterization for the TPM model used in the $M$-ratio test, we tested the entire sample of Buffbreasted Sandpipers for potential genetic bottlenecks.

Phylogeographic analysis using mtDNA data.-We successfully amplified and analyzed 967 bp of the cyt $b$ gene. We confirmed sequence identity by alignment with a published Buff-breasted Sandpiper cyt $b$ sequence (GenBank accession no. EF373162.1). We translated sequences from nucleotide to amino acid sequences in MEGA4 to confirm that sequences were fully coding with no frameshifts, no premature stop codons, and no evidence of pseudogene amplification (Rodríguez et al. 2007). We calculated standard molecular diversity indices (number of haplotypes, haplotype diversity, and nucleotide diversity) as well as Fu's $F_{\mathrm{S}}$ (Fu and Li 1993) and Tajima's $D$ (Tajima 1989) tests for selective neutrality in DNASP, version 5 (Librado and Rozas 2009). To determine phylogeographic patterns of gene flow, we also calculated $\Phi$ statistics in ARLEQUIN. To visualize phylogeographic patterns graphically, we constructed a minimum-spanning haplotype network in NETWORK, version 4.610 (Bandelt et al. 1999). We calculated the same indices for the 576-bp region of the mtDNA control region.

To estimate divergence time, we used several approaches for a range of mutation rates using the coding cyt $b$ gene. Because the molecular clock for cyt $b$ in Buff-breasted Sandpipers has not been estimated, we used the reported range for Charadriiformes proposed by Weir and Schluter (2008) of 1.59-4.31\% $\mathrm{Ma}^{-1}$. We used this range of mutation rates for $967 \mathrm{bp}$ of the cyt $b$ gene to estimate a range of mutation rates $\left(1.53-4.15 \%\right.$ substitutions site ${ }^{-1}$ year $\left.^{-1}\right)$. We used these mutation rates to estimate divergence times via the average number of mutations separating ancestral and descendent haplotypes (@-statistic) in NETWORK (Forster et al. 1996).
To test the validity of our estimates, we also employed a Bayesian coalescent-based approach to estimate divergence time in BEAST, version 1.6.2 (Drummond and Rambaut 2007). We used Akaike's information criterion to select the best-fit nucleotide substitution model for this gene in JMODELTEST, version 3.7 (Posada 2008). Last, using a Markov chain Monte Carlo approach and imposing a Bayesian skyline plot as our demographic model, we estimated divergence time to approximate the period when the population began to diverge from the most pervasive haplogroup. Results are presented as means \pm SD.

\section{Results}

Migratory and genetic connectivity.-Microsatellite characterization revealed polymorphisms at all nine loci (mean number of alleles $=8.89 \pm 4.96$; Table 1 ). Across the entire sample, four of the nine loci analyzed showed significant deviation from HWE because of heterozygosity deficit (sequential Bonferroni corrected $P=0.010$; Table 1). These same four loci showed evidence of null alleles according to MICRO-CHECKER $(P<0.010)$. No pairs of loci showed significant deviation from $\operatorname{LD}(P>0.001)$. Mean allelic dropout rate was $<1 \%$ across all loci.

For the Bayesian clustering analysis, individuals were admixed among the clusters at $K \geq 2$, with no individuals being strongly assigned to any one group. PCoA based on genetic distance explained $39.1 \%$ of variation among genotypes and indicated the absence of genetic structure (Fig. 2). Taken together, our results suggested that Buff-breasted Sandpipers are a single, panmictic population at a global scale. Thus, we assessed the coefficient of inbreeding using our entire sample. The resulting inbreeding coefficient was not significantly different from zero $\left(F_{\mathrm{IS}}=0.020, P>0.05\right)$. Moreover, summary statistics for temporal analyses of all samples did not indicate genetic differences in samples grouped by decade (1990s vs. 2000s). The mtDNA data supported microsatellite results, showing high levels of gene flow among regions $\left(\Phi_{\mathrm{ST}} \leq 0.000, P>0.30\right)$. An unrooted medianjoining haplotype network analysis indicated mtDNA admixture across the distributional range of the species (Fig. 3). A comparison of the principal coordinate space for genotypes among breeding, wintering, and migrating birds found no unique individual genotypes in migrating birds; all migrating individuals fell within the principal coordinate space of wintering and breeding birds (Fig. 2). This finding strongly suggests that unsampled populations from the breeding and wintering grounds were likely not genetically unique and further supports the inference that this is a panmictic population.

Within-region analyses further suggested high levels of genetic connectivity among geographically disjunct sites within the sampled breeding, migratory, and wintering regions. Microsatellite AMOVAs provided no evidence of population structure among breeding sites $(0.19 \%$ of variation explained among populations). For three Alaskan breeding sites, pairwise $F_{\mathrm{ST}}$ values indicated high levels of gene flow among all sites $\left(F_{\mathrm{ST}}=0.010, P>0.10\right)$. Similarly, pairwise $F_{\mathrm{ST}}$ values revealed high levels of gene flow among wintering sites in Argentina, Uruguay, and Brazil $\left(F_{\mathrm{ST}}=\right.$ $0.045, P>0.019)$. PCoA based on genetic distance among wintering-site individuals explained $41.8 \%$ of variation and supported an absence of substructure. When males were excluded from the 
All $(39.25 \%)$

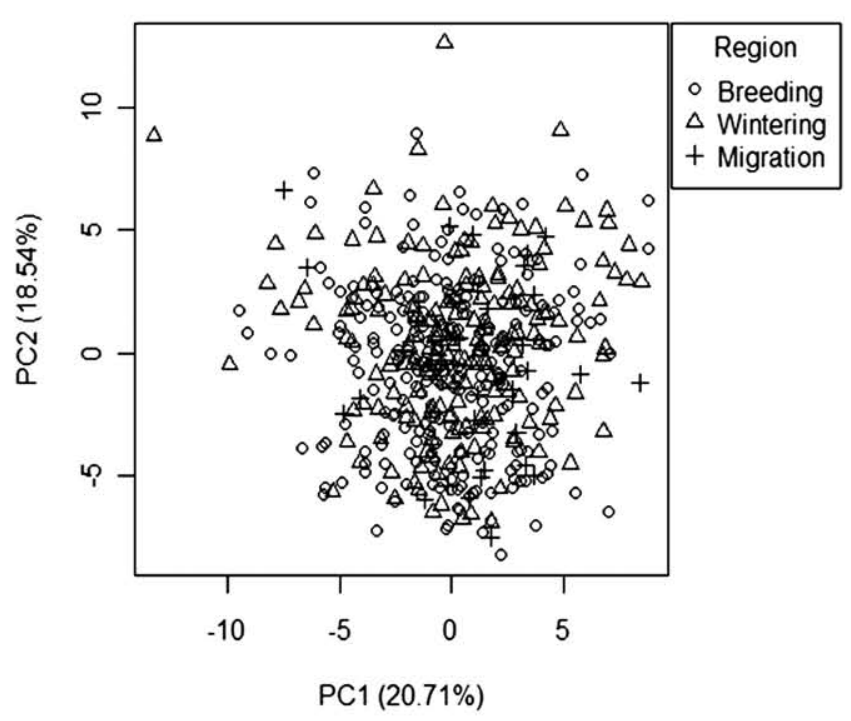

Winter $(41.75 \%)$

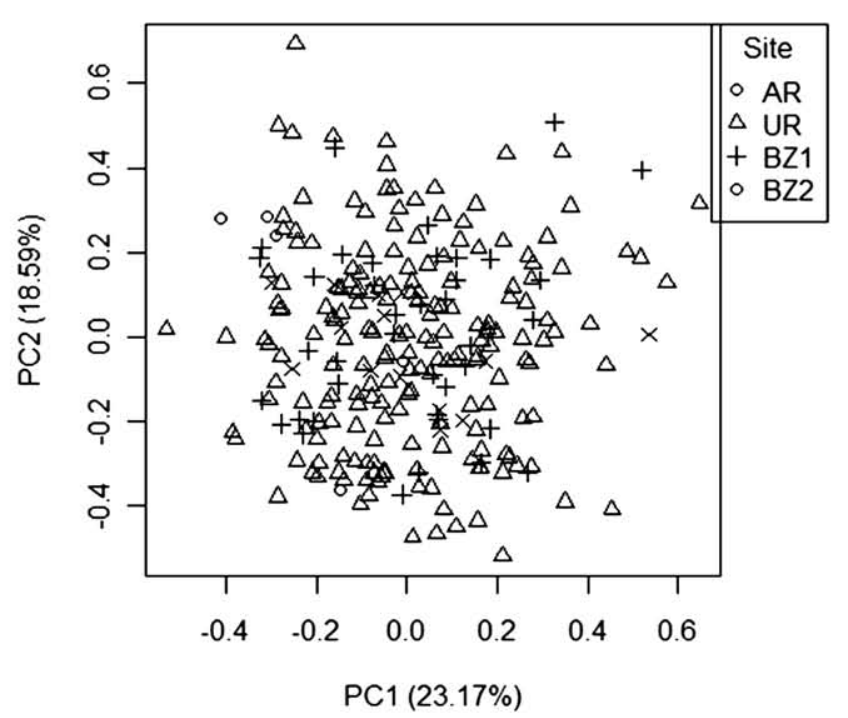

Breeding (39.99\%)

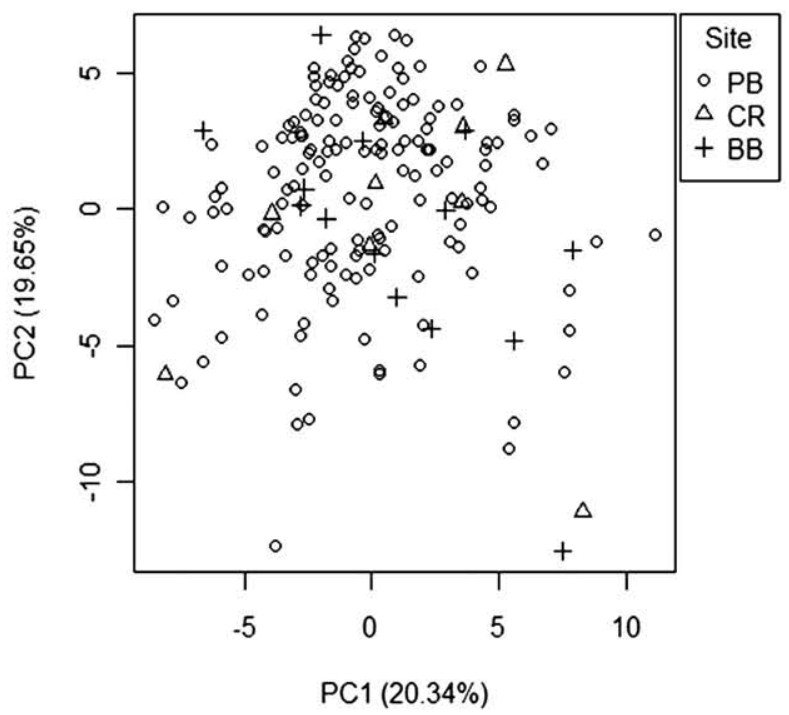

Migration (47.64\%)

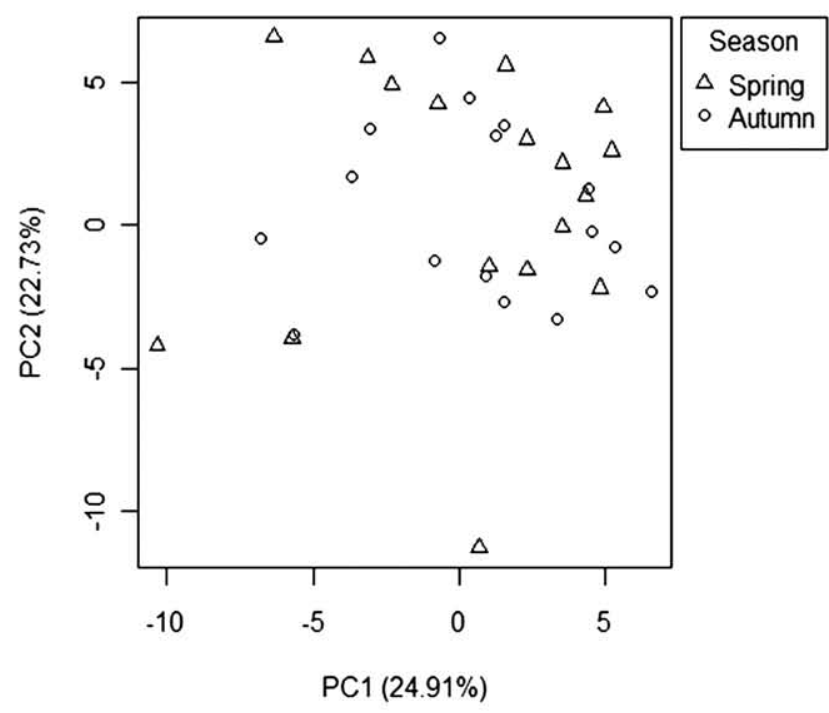

FIG. 2. Four principal coordinate analyses derived from microsatellite data based on genetic distance. The absence of coordinate space between clusters of individuals within each figure is indicative of admixture at all spatial scales. Percentage of variation explained by each principal coordinate (PC1 and PC2) and overall is in parentheses, associated with the axis and panel titles, respectively. Abbreviations: $\mathrm{PB}=\mathrm{Prudhoe} \mathrm{Bay}$; $\mathrm{CR}=\mathrm{Canning}$ River; $\mathrm{BB}=$ Barrow; $\mathrm{AR}=$ Argentina; UR = Uruguay; BZ1 = Lagoa do Peixe, Brazil; and BZ2 = Taim, Brazil.

sample, females did not show significant population structure between two wintering sites in Brazil $\left(F_{\mathrm{ST}}=0.002, P>0.41\right)$.

Population trend analyses.-Buff-breasted Sandpipers appeared to be one admixed population, and we included all individuals in the analysis of $N_{\mathrm{e}}$. Point estimates of $N_{\mathrm{e}}$ were highly variable, and upper confidence limits included infinity in both models, indicating violations of model assumptions. Thus, our estimates are not reliable and cannot be interpreted with confidence.

We found no evidence of a genetic bottleneck in our analyses. For the range of estimated pre-bottleneck effective population sizes, the observed $M$ ratio was significantly higher than $M_{\mathrm{c}}$ in all tests and provided no evidence of genetic bottlenecks 


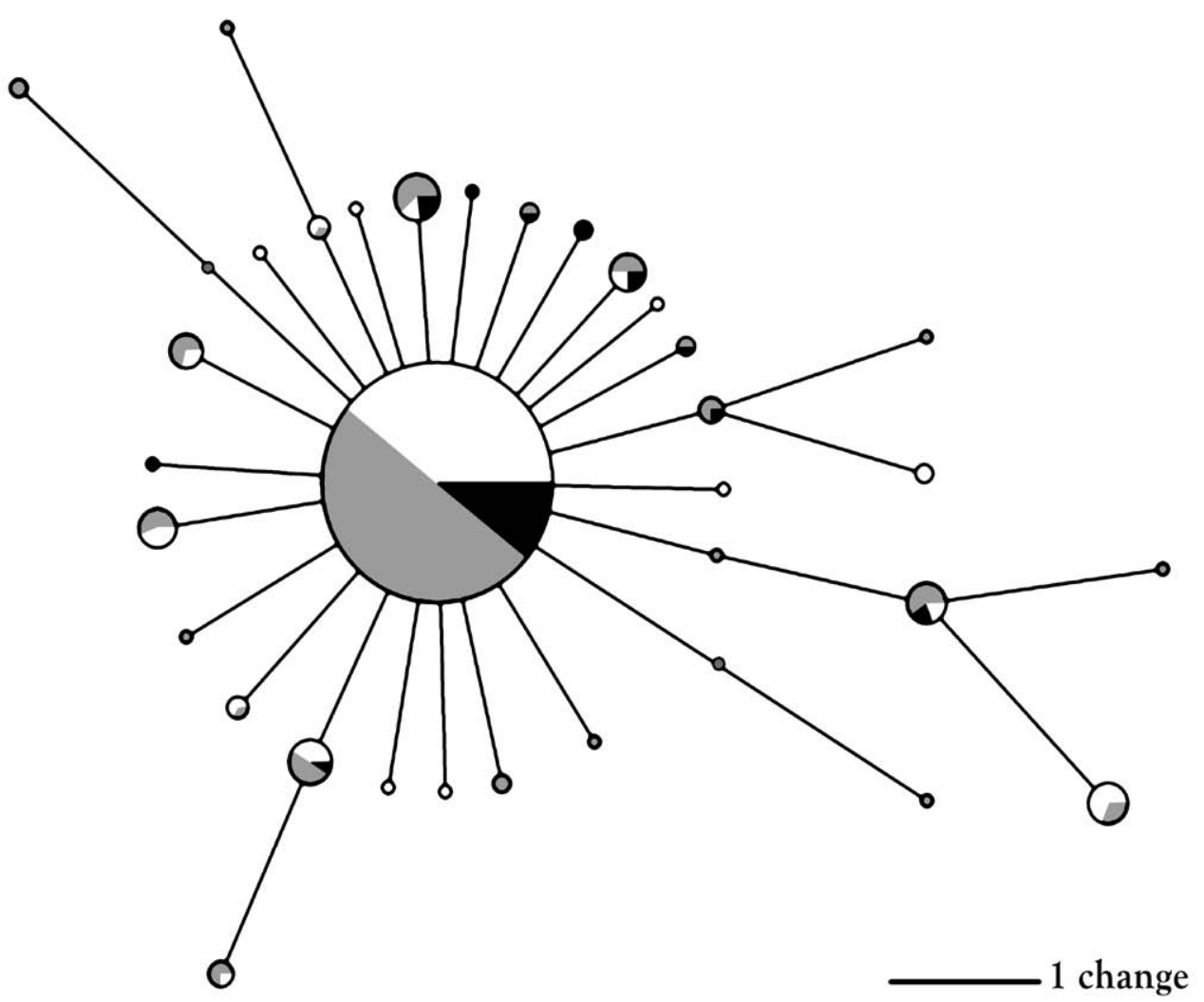

FIG. 3. Minimum-spanning haplotype network for the Buff-breasted Sandpiper based on a 967-bp region of the cytochrome $b$ gene in the mitochondrial genome ( $n=438$ birds). The absence of multiple pervasive haplotypes is indicative of a single, admixed evolutionarily significant unit. Node size indicates the relative number of individuals in each haplogroup, and branch length indicates number of mutations (standard branch length is 1 mutation). Nodes are color coded to correspond with stages of the annual cycle (white = breeding, black = migration, and gray $=$ wintering). Assumed mutations that were not found in our sample are represented by dark gray circles along branches.

$(P>0.10)$. Lack of bottlenecks was supported by a heterozygosity excess test (Wilcoxon test: $P>0.90$ ) and mode-shift indicator. Although population losses were observed at the turn of the 20th century, we found no evidence of a genetic bottleneck associated with the decline.

Phylogeography.-For the 438 Buff-breasted Sandpipers (90\% of the total sample) successfully sequenced at the cyt $b$ gene, mtDNA analysis revealed 31 variable sites producing 33 unique haplotypes (Table 2). We estimated an average haplotype diversity $\left(H_{\mathrm{d}}\right)$ of $0.436 \pm 0.030$ and nucleotide diversity $(\pi)$ of $7.20 \pm 6.00 \%$ (Table 2). A total of 328 individuals out of the total number sequenced (75\%) fell into the most predominant haplogroup (CB1). High haplotype diversity and low nucleotide diversity indicate populations that have undergone rapid demographic expansion after a population decline. To test for population growth in Buffbreasted Sandpipers, we conducted two tests for neutrality. Both tests were significant (Tajima's $D=-2.27, P<0.01$; Fu's $F_{\mathrm{S}}=-30.6$, $P<0.0001)$, indicating that this population likely underwent a population expansion from a single Pleistocene refugium.

Using an estimated value of the average number of mutations separating ancestral and descendent haplotypes (Q-statistic = $0.349 \pm 0.098$ ), we calculated a divergence time from the ancestral haplotype. Estimated divergence times ranged from 8,416 $( \pm 2,366)$ to $22,816( \pm 6,416)$ years before present $(\mathrm{BP})$, based on our range of mutation rates. To assess the validity of our estimates, we also combined two independent runs of $10^{8}$ iterations

TABLE 2. Molecular diversity indices for cytochrome $b$ and mtDNA control region for the global population of Buff-breasted Sandpipers ( $n=$ number of individuals, $h=$ number of haplotypes, $H_{\mathrm{d}}=$ haplotype diversity $\pm \mathrm{SD}$, and $\pi=$ nucleotide diversity $\pm \mathrm{SD}$ ).

\begin{tabular}{lccccccccc}
\hline & \multicolumn{4}{c}{ Cytochrome $b$} & & \multicolumn{4}{c}{ Control region } \\
\cline { 2 - 4 } Sampling site & $n$ & $h$ & $H_{\mathrm{d}}$ & $\pi \times 10^{3}$ & & $n$ & $h$ & $H_{\mathrm{d}}$ & $\pi \times 10^{3}$ \\
\hline Breeding & 166 & 18 & $0.39 \pm 0.05$ & $0.69 \pm 0.11$ & & 172 & 50 & $0.80 \pm 0.03$ & $3.17 \pm 0.27$ \\
Migration & 40 & 10 & $0.44 \pm 0.10$ & $0.57 \pm 0.15$ & 43 & 17 & $0.84 \pm 0.05$ & $3.16 \pm 0.49$ \\
Wintering & 232 & 24 & $0.47 \pm 0.01$ & $0.75 \pm 0.09$ & & 227 & 51 & $0.83 \pm 0.02$ & $3.27 \pm 0.22$ \\
All & 438 & 33 & $0.44 \pm 0.03$ & $0.72 \pm 0.01$ & & 449 & 74 & $0.82 \pm 0.02$ & $3.24 \pm 0.16$
\end{tabular}




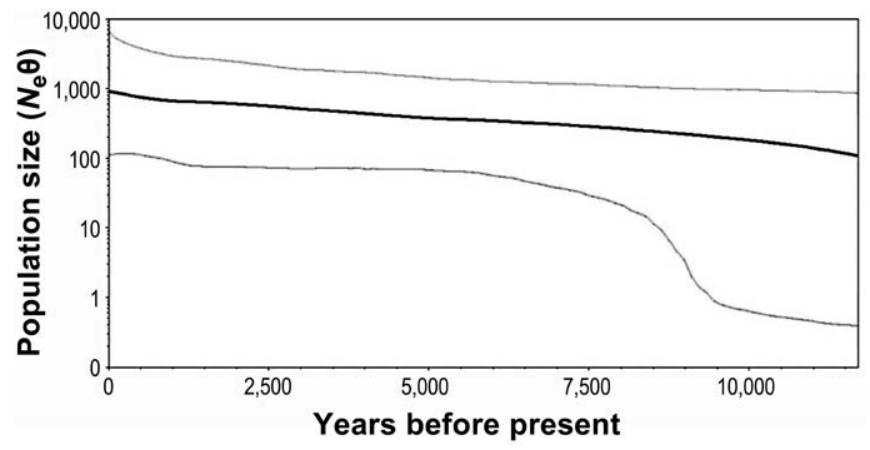

FIG. 4. Reconstruction of demographic population fluctuations based on a Bayesian skyline plot derived from cytochrome $b$ sequence data. A population experiencing fluctuations in effective size would show sharp, rapid changes over time rather than the smooth curve shown in this plot. The solid black line represents the median population size estimate $\left(N_{\mathrm{e}} \theta\right)$, and the solid gray lines represent the $95 \% \mathrm{Cl}$ around this estimate.

(discarding the first $10^{7}$ as burn-in) of a Bayesian coalescent-based approach for estimating divergence time. Using the TamuraNei model (TrN; Tamura and Nei 1993) of nucleotide substitution with invariable sites and gamma distribution and a relaxed log normal clock, we estimated population divergence time as $17,000-45,000$ years BP. Historical demographic patterns reconstructed using our Bayesian skyline plot analysis implied steady growth from this expansion (Fig. 4). The inference of population expansion from a single, small population is confirmed by the starburst topology of the haplotype network for cyt $b$ in the mitochondrial genome (Fig. 3).

The phylogeographic patterns inferred from the coding cyt $b$ gene were supported by analyses of the noncoding mtDNA control region. For 449 individuals ( $92 \%$ of total sample) successfully sequenced at the mitochondrial control region, analyses revealed 51 variable sites producing 74 unique haplotypes with average $H_{\mathrm{d}}=0.822 \pm 0.017$ and $\pi=3.24 \pm 1.6 \%$ (Table 2 ). Neutrality tests were also significant and supported inferences of population expansion from a single refugium drawn from cyt $b$ sequence data (Tajima's $D=-2.11, P<0.010$; Fu's $F_{\mathrm{S}}=-27.14, P<0.0001$ ).

\section{Discussion}

Migratory and genetic connectivity.-We found no signal of population structure in Buff-breasted Sandpipers among Arctic breeding sites in Alaska or among wintering sites in South America. Independent tests for population substructure using microsatellite data (Bayesian clustering, PCoA, Wright's F statistics, and AMOVA) and mtDNA sequence data ( $\Phi$ statistics) supported the inference that Buff-breasted Sandpipers are a single, admixed population with no population genetic structure associated with migratory connectivity. Buff-breasted Sandpipers captured at migration sites did not show evidence of unique alleles during either spring or autumn migration, which suggests that unsampled populations in the Arctic and in South America did not contribute unique population genetic signatures and are part of the panmictic population.

Recent population trend analysis.-Assessment of genetic demographic trends is a powerful tool for inferring the impacts of historical demographic processes on contemporary populations. To determine whether there was a genetic signal corresponding to the large historical population decline in Buff-breasted Sandpipers, we estimated the likelihood of a recent genetic bottleneck associated with an observed population bottleneck and modeled changes in effective population size over time. Our independent tests to detect an excess of heterozygotes did not provide evidence of a recent genetic bottleneck. Lack of a bottleneck was unexpected, considering the large historical and contemporary declines experienced by this migratory shorebird during the past 150 years. We suspect that although there were large declines because of market hunting at the turn of the last century, the genetic signal was obscured because of high levels of gene flow in this globally admixed species that likely contribute to a large effective population size (Trimbos et al. 2011). Population monitoring efforts have failed to provide precise estimates of the global population size of Buff-breasted Sandpipers; similarly, our estimates of $N_{\mathrm{e}}$ indicated violations of model assumptions, and we were unable to estimate the global effective population size for this species with precision.

Phylogeography and historical demography.-Understanding the historical demography of migratory birds is helpful for conducting effective conservation in the future. Linking patterns of phylogeographic structure to known historical events can help conservation biologists understand the forces that shape contemporary population structure, and this information can be used to prevent future losses of taxonomic diversity within species. Furthermore, because of the slower mutation rate of mtDNA in relation to microsatellites, it is possible to detect signals of genetic structure that are absent when assessing only microsatellite data.

Our estimates of divergence time for Buff-breasted Sandpipers suggest that the species began to radiate from a single glacial refugium between 8,400 and 45,000 years BP. The period of our estimate coincides with the Wisconsinan glaciation in North America (Munyikwa et al. 2011). This recent glaciation event ranged from $\sim 110,000$ to 10,000 years BP, when much of the Palearctic and eastern Nearctic region of the Buff-breasted Sandpiper's breeding region was covered with ice. Buff-breasted Sandpipers were likely confined to breed in a smaller region associated with the Beringia refugium during this time. Once the ice sheets began to retreat and additional breeding habitat became available, the population likely expanded and spread throughout the Arctic. Confinement followed by expansion was supported by the high haplotype diversity and low nucleotide diversity found in both mtDNA regions, as well as the significantly negative values from the independent tests for neutrality (Fu 1997). Demographic models over time also supported the steady increase in population size throughout the Holocene (Fig. 4). A historical demographic pattern can be visualized in the starburst topology found in our haplotype network for cyt $b$ (Avise 2009; Fig. 3). Similar phylogeographic patterns have been reported in other species of Arcticbreeding shorebirds, including Dunlin (Wenink et al. 1996) and Temminck's Stint (Rönkä et al. 2008).

Conservation status.-Moritz (1994) suggested that careful monitoring of both contemporary and historical conservation units is critical to effective species conservation, and an integrated approach is particularly important for migratory birds (Haig et al. 2011). We did not observe a signal of population structure on historical or contemporary scales within or among regions. Thus, we 
recommend that Buff-breasted Sandpipers should be managed as one conservation unit. Our analyses also indicated that this species has maintained high genetic variation, and this is an important aspect of maintaining population viability. Habitat fragmentation and degradation is occurring throughout the species' range, increasing the likelihood of population isolation and subdivision. Management efforts must focus on maintaining genetic connectivity by preventing population isolation across the distributional range of Buff-breasted Sandpipers, which would likely reduce the global effective population size and overall genetic variation (Lanctot et al. 2010).

\section{ACKNOWLEDGMENTS}

We thank C. Simmons, C. Ganser, T. Prebyl, and H. Barton for their assistance in the lab. We also thank the field crews and project leaders who helped with the major sampling efforts, especially C. T. Bernardo, S. Brown, B. Kempenaers, S. Kendall, G. S. Leal, A. Leist, M. S. Pereira, A. F. Pinto, F. Pöershke, U. B. Rasquin, L. Slater, and H. A. Swensen; the ranch owners who allowed us access to their private land, especially Sr. Dagoberto, Sr. Jorge, Mr. R. Bender, and the "Manduca" Machado family; H. A. Almeida, C. S. Fontana, as well as managers and staff of Parque Nacional da Lagoa do Peixe and Estação Ecológica do Taim for logistic support; and S. Fellows and S. Jones from U.S. Fish and Wildlife Service for funding the molecular ecology analyses. Funding for field work and lab analyses was provided by grants from the Neotropical Migratory Bird Conservation Act and the Migratory Bird Management programs of the U.S. Fish and Wildlife Service. Capture, transport, and handling of animals and tissues took place under applicable state and federal permits for wildlife research and followed protocols approved by the Institutional Animal Care and Use Committee at Kansas State University.

\section{Literature Cited}

AlmeidA, J. B. 2009. Wintering ecology of Buff-breasted Sandpipers (Tryngites subruficollis) in southern Brazil. Ph.D. dissertation, University of Nevada, Reno.

Andres, B. A., P. A. Smith, R. I. G. Morrison, C. L. GrattoTrevor, S. C. Brown, and C. A. FriIs. 2012. Population estimates of North American shorebirds, 2012. Wader Study Group Bulletin 119:178-194.

Avise, J. C. 2009. Phylogeography: Retrospect and prospect. Journal of Biogeography 36:3-15.

BAndelt, H.-J., P. Forster, AND A. RöHL. 1999. Median-joining networks for inferring intraspecific phylogenies. Molecular Biology and Evolution 16:37-48.

Bart, J., S. Brown, B. Harrington, and R. I. G. Morrison. 2007. Survey trends of North American shorebirds: Population declines or shifting distributions? Journal of Avian Biology 38:73-82.

Birdife International. 2009. Buff-breasted Sandpiper species factsheet. [Online.] Available at www.birdlife.org/datazone.

Butler, R. W., R. C. Ydenberg, G. D. Donaldson, And S. Brown. 2004. Hypotheses to explain census declines in North American shorebirds. Shorebird Research Group of the Americas Report 1. [Online.] Available at www.shorebirdresearch.org/ workinggroups.htm.
Carter, K. L., And B. Kempenaers. 2007. Eleven polymorphic microsatellite markers for paternity analysis in the Pectoral Sandpiper, Calidris melanotos. Molecular Ecology Notes 7:658-660.

Clark, N. A., C. D. T. Minton, J. W. Fox, K. Gosbell, R. B. LanCtot, R. R. Porter, and S. Yezerinac. 2010. The use of lightlevel geolocators to study wader movements. Wader Study Group Bulletin 117:173-178.

Cornuet, J. M., And G. Luikart. 1996. Description and power analysis of two tests for detecting recent population bottlenecks from allele frequency data. Genetics 144:2001-2014.

Davis, L. A., E. H. Roalson, K. L. Cornell, K. D. McClanahan, AND M. S. Webster. 2006. Genetic divergence and migration patterns in a North American passerine bird: Implications for evolution and conservation. Molecular Ecology 15:2141-2152.

Drummond, A. J., And A. Rambaut. 2007. BEAST: Bayesian evolutionary analysis by sampling trees. BMC Evolutionary Biology 7:214.

Excoffier, L., G. LAVAL, AND S. SCHNEIDER. 2005. Arlequin (version 3.0): An integrated software package for population genetics data analysis. Evolutionary Bioinformatics Online 1:47-50.

Forster, P., R. HARding, A. Torroni, ANd H.-J. BANDelt. 1996. Origin and evolution of Native American mtDNA variation: A reappraisal. American Journal of Human Genetics 59:935-945.

Franks, S. E., D. R. Norris, T. K. Kyser, G. Fernández, B. Schwarz, R. Carmona, M. A. Colwell, J. C. Sandoval, A. Dondua, H. R. Gates, And others. 2012. Range-wide patterns of migratory connectivity in the Western Sandpiper Calidris mauri. Journal of Avian Biology 43:155-167.

Friesen, V. L., T. M. Burg, And K. D. McCoy. 2007. Mechanisms of population differentiation in seabirds. Molecular Ecology 16:1765-1785.

FU, Y.-X.1997. Statistical tests of neutrality of mutations against population growth, hitchhiking and background selection. Genetics 147:915-925.

Fu, Y.-X., AND W.-H. LI. 1993. Statistical tests of neutrality of mutations. Genetics 133:693-709.

Garza, J. C., AND E. G. Williamson. 2001. Detection of reduction in population size using data from microsatellite loci. Molecular Ecology 10:305-318.

Haig, S. M., W. M. Bronaugh, R. S. Crowhurst, J. D’Elia, C. A. Eagles-Smith, C. W. Epps, B. Knaus, M. P. Miller, M. L. Moses, S. Oyler-McCANCE, ANd others. 2011. Genetic applications in avian conservation. Auk 128:205-229.

Haig, S. M., C. L. Gratto-Trevor, T. D. Mullins, and M. A. Colwell. 1997. Population identification of Western Hemisphere shorebirds throughout the annual cycle. Molecular Ecology 6:413-427.

HALl, T. A. 1999. BioEdit: A user-friendly biological sequence alignment editor and analysis program for Windows 95/98/NT. Nucleic Acids Symposium Series 41:95-98.

Jorgensen, J. G., J. P. MCCARty, And L. L. Wolfenbarger. 2008. Buff-breasted Sandpiper density and numbers during migratory stopover in the Rainwater Basin, Nebraska. Condor 110:63-69.

Lanctot, R. B., J. Aldabe, J. B. Almeida, D. Blanco, J. P. IsaCCh, J. Jorgensen, S. Norland, P. RocCA, And K. M. Strum. 2010. Conservation Plan for the Buff-breasted Sandpiper (Tryngites subruficollis). Version 1.1. U.S. Fish and Wildlife Service, Anchorage, Alaska, and Manomet Center for Conservation Sciences, Manomet, Massachusetts. 
Lanctot, R. B., M. Barter, C. Y. Chiang, R. Gill, M. JohnSon, S. Haig, Z. Ma, P. Tomkovich, ANd M. Wunder. 2009. Use of band resightings, molecular markers and stable isotopes to understand the migratory connectivity of Dunlin breeding in Beringia and wintering in the East Asian-Australasian Flyway. Pages 149-164 in Proceedings from the 2009 International Symposium on Coastal Wetlands and Water Birds Conservation. Endemic Species Research Institute, Nantou County, Republic of China (Taiwan).

Lanctot, R. B., D. E. Blanco, R. A. Dias, J. P. Isacch, V. A. Gill, J. B. Almeida, K. Delhey, P. F. Petracci, G. A. Bencke, And R. A. BAlbueno. 2002. Conservation status of the Buff-breasted Sandpiper: Historic and contemporary distribution and abundance in South America. Wilson Bulletin 114:44-72.

Lanctot, R. B., A. Hartman, L. W. Oring, and R. I. G. MorRISON. 2008. Response to Farmer (2008): Limitations of statistically derived population estimates, and suggestions for deriving national population estimates for shorebirds. Auk 125:983-985.

Lanctot, R. B., and C. D. Laredo. 1994. Buff-breasted Sandpiper (Tryngites subruficollis). In Birds of North America, no. 91 (A. Poole and F. Gill, Eds.). Academy of Natural Sciences, Philadelphia, and American Ornithologists' Union, Washington, D.C.

Lanctot, R. B., K. T. Scribner, B. Kempenaers, and P. J. WEATHERHEAD. 1997. Lekking without a paradox in the Buffbreasted Sandpiper. American Naturalist 149:1051-1070.

Librado, P., AND J. Rozas. 2009. DnaSP v5: A software for comprehensive analysis of DNA polymorphism data. Bioinformatics 25:1451-1452.

Liebers, D., AND A. J. Helbig. 2002. Phylogeography and colonization history of Lesser Black-backed Gulls (Larus fuscus) as revealed by mtDNA sequences. Journal of Evolutionary Biology 15:1021-1033.

MCIlhenny, E. A. 1943. Major changes in the bird life of southern Louisiana during sixty years. Auk 60:541-549.

Moritz, C. 1994. Defining 'evolutionarily significant units' for conservation. Trends in Ecology \& Evolution 9:373-375.

Morrison, R. I. G., B. J. McCaffery, R. E. Gill, S. K. Skagen, S. L. Jones, G. W. Page, C. L. Gratto-Trevor, and B. A. Andres. 2006. Population estimates of North American shorebirds. Wader Study Group Bulletin 111:67-85.

Munyikwa, K., J. K. Feathers, T. M. Rittenour, and H. K. SHRIMPTON. 2011. Constraining the Late Wisconsinan retreat of the Laurentide ice sheet from western Canada using luminescence ages from postglacial aeolian dunes. Quaternary Geochronology 6:407-422.

PAge, G. W., AND R. E. Gill, JR. 1994. Shorebirds in western North America: Late 1800s to late 1900s. Pages 147-160 in A Century of Avifaunal Change in Western North America (J. R. Jehl and N. K. Johnson, Eds.). Studies in Avian Biology, no. 15.

PARK, S. D. E. 2001. Trypanotolerance in West African cattle and the population genetic effects of selection. Ph.D. dissertation, University of Dublin, Dublin, Ireland.

Peakall, R., and P. E. Smouse. 2006. GenaleX 6: Genetic analysis in Excel. Population genetic software for teaching and research. Molecular Ecology Notes 6:288-295.

Pearce, J. M., K. G. McCracken, T. K. Christensen, and Y. N. ZHURAVLEV. 2009. Migratory patterns and population structure among breeding and wintering Red-breasted Mergansers
(Mergus serrator) and Common Mergansers (M. merganser). Auk 126:784-798.

Peel, D., J. R. Ovenden, And S. L. Peel. 2004. NeEstimator: Software for estimating effective population size, version 1.3. Queensland Government, Department of Primary Industries and Fisheries.

Posada, D. 2008. jModelTest: Phylogenetic model averaging. Molecular Biology and Evolution 25:1253-1256.

Pritchard, J. K., M. Stephens, and P. Donnelly. 2000. Inference of population structure using multilocus genotype data. Genetics 155:945-959.

RiCE, W. R. 1989. Analyzing tables of statistical tests. Evolution 43:223-225.

Rodríguez, F., J. Albornoz, And A. Domínguez. 2007. Cyt $b$ pseudogene originated from a highly divergent mitochondrial lineage in genus Rupicapra. Journal of Heredity 98:243-249.

Rönkä, A., L. Kvist, J. Karvonen, K. Koivula, V.-M. Pakanen, D. Schamel, And D. M. TRaCy. 2008. Population genetic structure in the Temminck's Stint Calidris temminckii, with an emphasis on Fennoscandian populations. Conservation Genetics 9:29-37.

Rönkë, N., L. Kvist, V.-M Pakanen, A. RönKä, V. Degtyaryev, P. Tomkovich, D. Tracy, And K. KoIvula. 2012. Phylogeography of the Temminck's Stint (Calidris temminckii): Historical vicariance but little present genetic structure in a regionally endangered Palearctic wader. Diversity and Distributions 18:704-716.

SCHUElKe, M. 2000. An economic method for the fluorescent labeling of PCR fragments. Nature Biotechnology 18:233-234.

Skagen, S. K., P. B. Sharpe, R. G. Waltermire, and M. B. Dillon. 1999. Biogeographical profiles of shorebird migration in midcontinental North America. Biological Science Report USGS/BRD/BSR2000-0003. U.S. Government Printing Office, Denver, Colorado.

STRUM, K. M. 2008. Exposure of migratory shorebirds to organophosphorus and carbamate pesticides at migratory migration and non-breeding sites in the Western Hemisphere. M.S. thesis, Kansas State University, Manhattan.

Strum, K. M., M. J. Hooper, K. A. Johnson, R. B. Lanctot, M. E. ZaCCAGNini, AND B. K. SANDERCOCK. 2010. Exposure of nonbreeding migratory shorebirds to cholinesterase-inhibiting contaminants in the Western Hemisphere. Condor 112:15-28.

TAJima, F. 1989. Statistical method for testing the neutral mutation hypothesis by DNA polymorphism. Genetics 123:585-595.

Tamura, K., J. Dudley, M. Nei, and S. Kumar. 2007. MEGA4: Molecular Evolutionary Genetics Analysis (MEGA) software version 4.0. Molecular Biology and Evolution 24:1596-1599.

TAmura, K., AND M. NeI. 1993. Estimation of the number of nucleotide substitutions in the control region of mitochondrial DNA in humans and chimpanzees. Molecular Biology and Evolution 10:512-526.

Trimbos, K. B., C. J. M. Musters, Y. I. Verkuil, R. Kentie, T. Piersma, AND G. R. DE SNOo. 2011. No evident spatial genetic structuring in the rapidly declining Black-tailed Godwit Limosa limosa limosa in The Netherlands. Conservation Genetics 12:629-636.

U.S. Shorebird Conservation Plan. 2004. High priority shorebirds-2004. U.S. Fish and Wildlife Service, MBSP 4107, Arlington, Virginia.

van Oosterhout, C., W. F. Hutchinson, D. P. M. Wills, And P. SHIPLEY. 2004. MICRO-CHECKER: Software for identifying 
and correcting genotyping errors in microsatellite data. Molecular Ecology Notes 4:535-538.

WAPLES, R. S., AND C. Do. 2008. LDNE: A program for estimating effective population size from data on linkage disequilibrium. Molecular Ecology Resources 8:753-756.

Waples, R. S., ANd M. ҮокотA. 2007. Temporal estimates of effective population size in species with overlapping generations. Genetics 175:219-233.

Webster, M. S., P. P. Marra, S. M. Haig, S. Bensch, and R. T. Holmes. 2002. Links between worlds: Unraveling migratory connectivity. Trends in Ecology \& Evolution 17:76-83.
Weir, J. T., AND D. SChluter. 2008. Calibrating the avian molecular clock. Molecular Ecology 17:2321-2328.

Wenink, P. W., A. J. Baker, H.-U. Rosner, And M. G. J. Tilanus. 1996. Global mitochondrial DNA phylogeography of Holarctic breeding Dunlins (Calidris alpina). Evolution 50:318-330.

Wennerberg, L., G. Marthinsen, and J. T. Lifjeld. 2008. Conservation genetics and phylogeography of southern Dunlins Calidris alpina schinzii. Journal of Avian Biology 39: 423-437.

Associate Editor: L. Joseph

APPENDIX. Primer pairs for each of five regions' amplified and optimal annealing temperatures $\left({ }^{\circ} \mathrm{C}\right)$.

\begin{tabular}{llll}
\hline Region & Forward primer & Reverse primer & ${ }^{\circ} \mathrm{C}$ \\
\hline Cytochrome $b$ 1 & 5'-TAGGATCATTCGCCCTATCCAT-3' & 5'-CGAAAGCGGTTGCTATTAG-3' $^{\prime}$ & 56 \\
Cytochrome $b$ 2 & 5'-TGGAATACAGGAGTCATCC-3' & 5'-GAAGTTTTCTGGGTCTCC-3' & 56 \\
Cytochrome $b$ 3 & 5'-CTCTTCCTACTAACCCTTG-3' & 5'-TAAAGTAGGTGAGGGATGCTAGT-3' $^{\prime}$ & 56 \\
Control region 1 & 5'-GCATGTAATTTGGGCATTTTTTG-3' & 5'-ATTTCACGTGAGGAGCT-3' & 58 \\
Control region 2 & 5'-CGAAATACATACAAGCCG-3' & 5'-CCTGAGGGCCAAAATAAG-3' & 50 \\
\hline
\end{tabular}

